\title{
Estratégia para destinação de resíduos sólidos recicláveis provenientes de universidades brasileiras
}

\author{
Strategy for the destination of recyclable solid waste from \\ brazilian universities
}

Estrategia para destinación de residuos sólidos reciclables provenientes de universidades brasileñas

Eloainy Alves Eustáquio ${ }^{1}$

Vanessa Felipe de Souza ${ }^{2}$ Danila Fernanda Rodrigues Frias ${ }^{3}$

${ }^{1}$ Mestrado em Ciências Ambientais pela Universidade Brasil. Graduação em Administração pelo Centro Universitário do Triângulo. E-mail: eloainy@gmail.com, Orcid http://orcid.org/0000-0001-5171-137X

${ }^{2}$ Doutorado e mestrado em Medicina Veterinária Preventiva - Virologia, e graduação em Medicina Veterinária pela Universidade Federal do Rio Grande do Sul (UFRGS). Pesquisadora nível A na Empresa Brasileira de Pesquisa Agropecuária (EMBRAPA), unidade Gado de Corte, Campo Grande,

MS. Experiência na área de Medicina Veterinária com ênfase em Doenças Infecciosas de Animais, atuando principalmente nos temas: Medicina Veterinária Preventiva, Virologia, Saúde Animal, Saúde Pública Veterinária, Educação Sanitária e Bem-estar Animal. E-mail: vanessa.felipe@embrapa.br,

Orcid: http://orcid.org/0000-0002-5215-8577

${ }^{3}$ Doutorado e mestrado em Medicina Veterinária pela Universidade Estadual Paulista Júlio de Mesquita Filho (UNESP). Graduação em Medicina Veterinária pela Universidade Brasil. Professor titular da Universidade Brasil. Experiência na área de Medicina Veterinária com ênfase em Medicina Veterinária Preventiva. E-mail: danila.frias@universidadebrasil.edu.br, Orcid: http://orcid.org/0000-0001-8621-3338 
Resumo: A coleta seletiva é uma prática sustentável, combate o desperdício e preserva o ambiente. Com base nisso, objetivamos propor uma estratégia de ação voltada à coleta seletiva em universidades. Segundo dados obtidos na Universidade Federal de Uberlândia e cooperativas de catadores, em 2015, foram produzidos 266.762 kg de material reciclável e arrecadados $\mathrm{R} \$ 231.252,53$ com a venda destes, por um custo de implantação de R\$ 55.330,00. A análise desse modelo resultou na produção do Guia de Implantação e Manutenção de um Sistema de Coleta Seletiva Aplicado a universidades brasileiras, pois constatou-se a importância da adoção de sistemas ativos de reciclagem em universidades, seja pelo grande volume de resíduos gerados, bem como pelos benefícios de sua implantação.

Palavras-chave: coleta seletiva; educação ambiental; reciclagem; sustentabilidade.

\begin{abstract}
Selective waste collection is a sustainable practice, fights waste and preserves the environment. Based on this fact, we aim to propose a strategy of action focused on selective collection at universities. According to the data obtained at both the Federal University of Uberlandia and waste collectors cooperative, in 2015, 266,762 kg of recyclable material was produced and from the sale of this material, $\mathrm{R} \$ 231,252.53$ was collected at a cost of $R \$ 55,330.00$. The analysis of this model resulted in the production of the Guide for Implementation and Maintenance of a Selective Collection System Applied to Brazilian Universities. This is due to the verified importance of the adoption of active systems of recycling in universities, as much as the benefits of its implementation.
\end{abstract}

Keywords: selective collection; environmental education; recycling; sustainability.

Resumen: La recolección selectiva es una práctica sostenible, combate el desperdicio y preserva el ambiente. Con base en ello, pretendemos proponer una estrategia de acción dirigida a la colecta selectiva en universidades. Según datos obtenidos en la Universidad Federal de Uberlândia y cooperativas de recolectores, en 2015, se produjeron $266.762 \mathrm{~kg}$ de material reciclable y recaudados $\mathrm{R} \$ 231.252,53$ con la venta de estos, por un costo de implantación de $\mathrm{R} \$ 55.330,00$. El análisis de este modelo resultó en la producción de la Guía de Implantación y Mantenimiento de un Sistema de Recolección Selectiva Aplicada a Universidades brasileñas, pues se constató la importancia de la adopción de sistemas activos de reciclaje en universidades, sea por el gran volumen de residuos generados, así como por los beneficios de su implantación.

Palabras clave: recolección selectiva; educación ambiental; reciclaje; sostenibilidad. 


\section{INTRODUÇÃO}

O crescimento da população urbana e a forte industrialização ocorrida no século passado contribuíram para o aumento da produção de resíduos das mais diversas naturezas. Entretanto, o acúmulo desses resíduos causa um processo de deterioração ambiental e, consequentemente, resulta em implicações na qualidade de vida dos seres humanos e animais.

O gerenciamento integrado dos resíduos sólidos (RS) é de fundamental importância para garantir a qualidade de vida da sociedade, bem como para um desenvolvimento sustentável. Dessa forma, um dos desafios da humanidade atualmente é preservar seu padrão de vida e manter o desenvolvimento tecnológico sem esgotar os recursos naturais do planeta. Nesse sentido, emerge a coleta seletiva de materiais recicláveis como uma alternativa para diminuir o impacto da produção de resíduos e proporcionar o desenvolvimento socioeconômico e ambiental.

Para minimizar a produção de resíduos, deve-se aplicar o uso dos "3Rs". Primeiramente, "Reduzir" o resíduo para evitar o desperdício e, em seguida, "Reaproveitar" tudo o que for possível antes do descarte e, por fim, promover a destinação dos materiais reaproveitáveis para "Reciclar".

Assim, uma das alternativas para diminuir o impacto da produção de resíduos e proporcionar o desenvolvimento socioeconômico e ambiental é a coleta seletiva de materiais recicláveis. A coleta seletiva consiste na separação dos resíduos para que estes sejam reciclados, o que pode ser feito por um único cidadão ou organizado em comunidades.

A reciclagem é um processo industrial que converte o resíduo descartado em produto semelhante ao inicial ou em outro. $\mathrm{O}$ ato de reciclar auxilia na economia de energia, contribui para poupar recursos naturais e trazer de volta ao ciclo produtivo o que é jogado fora.

A palavra reciclagem foi introduzida ao vocabulário internacional no final da década de 1980, quando foi constatado que as fontes de petróleo e outras matérias-primas não renováveis estavam se esgotando.

A gestão dos Resíduos Sólidos no Brasil intensificou-se após a promulgação de lei que instituiu a Política de Resíduos Sólidos no país, delimitando, além da gestão e manejo adequados dos resíduos, prazos para que os 
órgãos e autarquias públicas implantassem um decreto para regulamentar a separação dos resíduos recicláveis descartados pelos órgãos e entidades da administração pública federal direta e indireta, na fonte geradora, e a sua destinação às associações e cooperativas dos catadores de materiais recicláveis.

Assim, a implantação da coleta seletiva solidária constitui-se hoje em uma ação obrigatória dos órgãos públicos federais com o intuito de diminuir prejuízos na logística reversa de resíduos comuns e aumentar a viabilização de recursos financeiros para promover a inclusão social de fato. Necessário se faz, então, o empenho político dos dirigentes e de todos os integrantes da instituição para assumir suas responsabilidades organizacionais, buscando atender critérios ambientais de adequação dos contratos públicos às concepções de consumo sustentável, recusando materiais e atitudes que degradem o meio ambiente na sua extração ou no seu descarte, e adotando novas práticas licitatórias por meio da especificação detalhada de objetos com requisitos voltados à sua conservação e preservação.

A comprovação da viabilidade econômica de programas de coleta seletiva tem sido um grande desafio para gestores da área. Nessa perspectiva, para analisar as vantagens econômicas e financeiras desses programas, devem-se considerar os custos e benefícios resultantes do processo. Com esse objetivo, propomos uma estratégia de ação para coleta seletiva de RS para universidades do Brasil, considerando o desenvolvimento socioeconômico e ambiental de cada região, utilizando como modelo o sistema já instalado na Universidade Federal de Uberlândia (UFU), por meio da estimativa de custos e da avaliação dos impactos resultantes de sua implantação.

\section{METODOLOGIA}

O trabalho foi desenvolvido no município de Uberlândia, Estado de Minas Gerais, nos três campi da Universidade Federal de Uberlândia.

Inicialmente foi realizado um estudo descritivo retrospectivo por meio de levantamento de dados relativos à implantação do sistema de coleta seletiva adotado na Universidade Federal de Uberlândia, os quais foram disponibilizados pelo Departamento de Sustentabilidade da UFU. 
Os documentos institucionais utilizados para realização da pesquisa foram o Projeto Básico de Coleta Seletiva da UFU e sua resolução interna, que estabelece a Política Ambiental da Universidade, o Regulamento Interno da Comissão Institucional para Gestão e Educação Ambiental, bem como os contratos de prestação de serviços das cooperativas.

Foram obtidos, ainda, os dados relacionados à quantidade de alunos e servidores de cada Campus, o quantitativo e a estimativa de depreciação das lixeiras instaladas, a estratégia de distribuição adotada das lixeiras por Campus e a quantidade de resíduos coletados.

Nas cooperativas de catadores contratadas pela UFU para remoção do material de seus campi, também foi realizado um levantamento de dados relacionados à quantidade e tipo de material recolhido mensalmente, tendo como referência o período de fevereiro de 2013 a dezembro de 2015.

Após obtenção das informações junto ao Departamento de Sustentabilidade da UFU, bem como junto às cooperativas de catadores, aquelas foram transcritas e tabuladas em planilhas eletrônicas (software Excel) para posterior tratamento.

Com os dados já tabulados, foi realizado o cálculo de custos de implantação de um sistema de coleta seletiva, baseado no modelo adotado pela UFU e em valores obtidos por meio de pesquisa de mercado, na qual foram obtidos orçamentos fornecidos por empresas da iniciativa privada que oferecem serviços relacionados com armazenamento de resíduos. Ao final, procedeu-se à análise de viabilidade de otimização dos custos de implantação do sistema.

Para avaliar os impactos sociais, ambientais e econômicos da implantação de um sistema de coleta seletiva de RS em universidades do Brasil, foi conduzido um estudo sobre o tipo e características dos materiais coletados com relação à estimativa de tempo de degradação dos mesmos no meio ambiente.

As informações obtidas após o levantamento de dados, o cálculo de custos e a avaliação de impacto ambiental foram utilizadas para compor um material de divulgação e orientação sobre a coleta seletiva de resíduos, no formato de um guia, o qual contém elementos e subsídios para implantação do sistema em universidades brasileiras. 


\section{RESULTADOS E DISCUSSÃO}

\subsection{Levantamento de dados junto ao Departamento de Sustentabilidade da UFU}

A administração pública tem adotado o compromisso de desenvolver estratégias que contribuam com os desafios relacionados às questões ambientais e que promovam uma gestão voltada ao desenvolvimento sustentável. Nesse sentido, o presente estudo permitiu analisar os resultados da implantação do programa de coleta seletiva na Universidade Federal de Uberlândia sob os aspectos legais, financeiros, sociais e ambientais.

Após a análise dos documentos disponibilizados pela UFU, evidenciou-se a importância da organização para a implantação de um sistema de coleta seletiva, a exemplo dessa instituição, que expediu uma resolução interna, na qual fica estabelecida sua Política Ambiental. Essa resolução foi criada com o propósito de regulamentar as ações voltadas para o desenvolvimento sustentável e, principalmente, a segregação e destinação dos resíduos recicláveis. A Universidade aprovou também um Regulamento Interno para reger uma comissão institucional para gestão e educação ambiental. A referida comissão ficou encarregada da supervisão da implementação da Política Ambiental da UFU e, em conformidade com o Projeto Básico, implantou o sistema de coleta seletiva de RS.

Esse sistema foi efetivado com a participação voluntária de professores, técnico-administrativos, estudantes e, principalmente, funcionários que coordenaram o recolhimento dos materiais nos prédios. A introdução dessas ações contribuiu para a preservação do meio ambiente por meio da execução da adequada coleta dos resíduos, e também da conscientização, sensibilização e mobilização da comunidade universitária em favor dos valores e atitudes ambientalmente corretos. Esse trabalho de educação se mostrou altamente relevante para que o sistema de reciclagem funcionasse, pois favoreceu a conscientização da população acadêmica sobre sua participação em separar os resíduos aproveitáveis destinados às usinas de reciclagem (GRIPPI, 2001).

Um dos projetos criados com vistas à participação e conscientização da comunidade acadêmica foi denominado "Formação de Agentes Ambientais". 
Esse projeto foi uma iniciativa da Divisão de Assistência ao Estudante da UFU, tendo sido selecionados alunos dos campi de Uberlândia que participaram de Curso de Formação. Esses alunos assistiram a aulas sobre conteúdos da área de meio ambiente e sustentabilidade, bem como participaram de atividades práticas em projetos, elaborando iniciativas ou realizando ações. Segundo relatado por Tauchen e Brandli (2006), as Instituições de Ensino Superior, já há algum tempo, vêm se preocupando com o desenvolvimento sustentável e realizando ações de gestão ambiental com a utilização de abordagem educacional, preparando estudantes por meio do fornecimento de informações e conhecimento sobre gestão ambiental.

Todo o processo de educação ambiental deve conscientizar a comunidade acadêmica para a não geração, bem como aplicação dos 3Rs, tratamento e disposição final adequada dos RS gerados na Instituição. Como afirmou Bittencourt (2014), a educação ambiental não pode apenas transmitir informações e conteúdos, mas propiciar aprendizados e mudanças culturais. Da mesma forma, as Instituições de Ensino Superior devem praticar o que ensinam e não serem vistas apenas como instituições estagnadas e burocráticas (CARETO; VENDEIRINHO, 2003).

O serviço de coleta seletiva da UFU foi implantado inicialmente nos 3 (três) campi de Uberlândia, nos seguintes pontos de coleta: Campus Santa Mônica, Campus Umuarama e Hospital de Clínicas de Uberlândia, e Campus Educação Física. Nesses locais, os resíduos foram separados na origem, em coletores apropriados e dispostos pelos campi. Todo o resíduo seco (papel, plástico, metal e vidro) deveria ser colocado em sacos verdes ou azuis, e levados a um Eco Ponto, onde permanecia armazenado até a retirada pelas associações e cooperativas participantes do projeto.

Na UFU, as empresas prestadoras de serviços de limpeza são responsáveis por promover o transbordo dos resíduos retirados dos coletores até os locais de acondicionamento, os quais estão instalados em locais apropriados que facilitam o acesso de veículos para que as associações e cooperativas habilitadas realizem a coleta.

Na implantação do programa, foram instalados 103 (cento e três) pares de coletores seletivos, cada um com capacidade de 100 litros, distribuídos nos três campi. 
Para o acondicionamento dos resíduos coletados nas lixeiras, foram comprados, em 2015, dez contêineres, com capacidade de 1000 litros cada um, os quais estão alocados nos Eco Pontos.

Em 2015, dez contêineres com capacidade individual de 1000 litros foram distribuídos nos Eco Pontos para o acondicionamento dos resíduos coletados nas lixeiras. A quantidade de resíduos produzido nos três campi de Uberlândia, assim como a comunidade acadêmica (alunos e servidores) correspondente, está discriminada na Tabela 1.

Tabela 1 - Quantidade de resíduos coletados e comunidade acadêmica dos campi da UFU na cidade de Uberlândia, MG, durante os anos de 2013 a 2015

\begin{tabular}{c|c|c}
\hline ANO & VOLUME RESÍDUOS (kg) & № ALUNOS/SERVIDORES \\
\hline 2013 & 132.696 & 25.676 \\
\hline 2014 & 191.533 & 26.172 \\
\hline 2015 & 266.762 & 24.487 \\
\hline
\end{tabular}

Fonte: os próprios autores.

Com relação à produção de resíduo, observamos que, no ano de 2013, essa produção foi de 5,16 kg/indivíduo. Já no ano de 2014, foi de 7,31 kg/ indivíduo, e, em 2015, foi de 10,90 kg/indivíduo. Em estudo semelhante realizado na Universidade Federal de Feira de Santana, em 2001, a produção de resíduos recicláveis por indivíduo foi de $5,5 \mathrm{~kg}$ e, segundo os autores, esse volume baixo foi devido à falta de incentivo à coleta seletiva (FURIAM; GÜNTHER, 2006).

Um fato interessante observado na UFU foi o aumento da anual da produção de resíduos. Esse fenômeno vem ocorrendo em vários lugares do mundo como, por exemplo, em alguns países pertencentes à Comunidade Europeia, com aumento do volume de resíduos em cerca de $10 \%$ ao ano (COMISSÃO EUROPÉIA, 2000). Contudo deve-se ter cautela ao afirmar que o aumento da geração dos resíduos seja apenas reflexo do consumo. Devido à realização de trabalhos de educação ambiental e conscientização desenvolvida pela Universidade, acredita-se que não houve aumento da produção de resíduos, mas que a comunidade acadêmica passou a exercer 
a prática da reciclagem por meio da segregação dos RS que, anteriormente, era desprezado como resíduo úmido.

De acordo com pesquisa realizada por Rodrigues e Leite (2008), o espaço necessário para armazenar $1 \mathrm{~kg}$ de material reciclável é de 0,01 $\mathrm{m}^{3}$. $\mathrm{Na}$ UFU, no ano de 2015, foram produzidos, diariamente, cerca de $730 \mathrm{~kg}$ de material reciclável, totalizando 5.110 kg semanais. O espaço necessário para armazenamento desse material seria de $51 \mathrm{~m}^{3}$, mas o disponibilizado foi de 10 contêineres de 1000 litros cada $\left(10 \mathrm{~m}^{3}\right.$ ), além de 103 lixeiras de 100 litros cada $\left(10 \mathrm{~m}^{3}\right)$, totalizando $20 \mathrm{~m}^{3}$. Aparentemente, o espaço seria insuficiente para atender à demanda, mas essa questão foi sanada com a retirada do material durante três vezes por semana, ou seja, a cada 2,5 dias. Nesse caso, o volume necessário para armazenamento desse material seria de $18 \mathrm{~m}^{3}$, o que é atendido pela capacidade dos contêineres e lixeiras distribuídos pelos campi da UFU.

Com relação à quantidade de indivíduos circulantes diariamente pela Universidade e a quantidade de lixeiras distribuídas, observou-se a proporção de um par de lixeiras para 247 indivíduos, sendo essa proporção suficiente para atender toda a demanda, com a totalidade dos resíduos sendo destinada à reciclagem.

Todo material reciclável coletado na UFU é doado, e, para regularizar as doações, a Universidade celebrou um contrato de prestação de serviços especializados em coleta seletiva de RS. Nesse contrato, foram acordadas a execução da coleta, o transporte, a triagem e o processamento dos resíduos recicláveis gerados nos três campi de Uberlândia, tendo como colaboradores principais as cooperativas de catadores.

Essa parceria foi fundamental para o sucesso da Política Ambiental da Universidade. Destaca-se aqui que a valorização do trabalho das cooperativas de catadores deve ser pensada sob uma ótica socioambiental, pois esse trabalho, além de minimizar os impactos ambientais, fomenta a mobilização e a inclusão social de cidadãos marginalizados, por meio do aumento da geração de renda dos cooperados (BRASIL, 2008).

De acordo com o Projeto Básico de Coleta Seletiva da UFU, a coleta deveria ser realizada pelas entidades habilitadas, nos períodos de atividades letivas da UFU e do HCU/UFU, preferencialmente, entre as 13 horas e 17 horas, três vezes por semana. 


\subsection{Custos da implantação do sistema de coleta seletiva na UFU}

Para iniciar o sistema de coleta seletiva da UFU, foram instalados 103 pares de coletores seletivos que a universidade já possuía. Esses coletores foram reformados e adaptados para serem distribuídos nos campi de Uberlândia. O valor total investido para reforma dos coletores no ano de 2013 foi de $\mathrm{R} \$ 25.610,00$, ou seja, cada lixeira custou R\$124,32. Atualmente, o custo médio de um par de coletores novos é de R\$399,00. Assim, o custo atualizado de implantação de 103 pares de coletores seria de $\mathrm{R} \$$ 41.097,00. Uma informação importante é que, do período da implantação até outubro de 2016, os coletores não se depreciaram, portanto não foi necessário realizar novas compras para substituí-los.

Para que o material coletado nas lixeiras fosse armazenado nos Eco Pontos, foi realizada, no ano de 2015, a compra de 10 contêineres com capacidade de 1000 litros, no valor unitário de $\mathrm{R} \$$ 1.423,38, totalizando $\mathrm{R} \$ 14.233,00$. Assim, o custo final de implantação de um sistema de coleta seletiva semelhante ao da UFU, com 103 pares de lixeiras e 10 contêineres para suprir a necessidade de coleta seletiva de uma comunidade acadêmica de 25.500 indivíduos seria de $\mathrm{R} \$ 55.330,00$.

Para a realização de serviços de coleta, transporte, triagem e processamento dos resíduos, a Universidade Federal de Uberlândia firmou contrato com as cooperativas. Conforme consta no contrato, essas cooperativas realizariam o serviço, e a UFU, por sua vez, faria o pagamento no valor de R\$ $310,00 /$ tonelada de material retirado dos seus campi. Esse serviço gerou um custo anual para a UFU de R\$ 41.135,00, no ano de 2013. No ano de 2014, esse valor foi de $\mathrm{R} \$ 59.375,00$, e, em 2015, de $\mathrm{R} \$ \mathbf{8 2 . 6 9 6 , 0 0}$. Os valores relacionados a esses serviços são elevados, sendo esse o principal entrave para se implantar um sistema de coleta seletiva em empresas utilizando-se a aplicação da logística reversa (IPEA, 2012).

\subsection{Levantamento de dados junto às cooperativas de catadores}

Na Tabela 2, estão descritos os tipos e as quantidades de resíduos sólidos recolhidos pelas cooperativas, entre 2013 e 2015. A justificativa da ausência do alumínio se dá em virtude do recolhimento do material por 
catadores autônomos, antes de serem separados pela empresa terceirizada responsável pela limpeza dos campi.

Tabela 2 - Tipo de resíduos e quantidade ( $\mathrm{kg}$ ) coletada nos campi da UFU na cidade de Uberlândia, MG, de 2013 a 2015

\begin{tabular}{l|c|c|c}
\multicolumn{1}{c|}{ TIPO DE RESÍDUOS SÓLIDOS } & $\mathbf{2 0 1 3}$ & $\mathbf{2 0 1 4}$ & $\mathbf{2 0 1 5}$ \\
\hline Papelão & 48.906 & 59.097 & 80.715 \\
\hline Sucata (peças metálicas) & 4.671 & 10.396 & 13.067 \\
\hline Papel Branco & 38.233 & 35.652 & 58.390 \\
\hline Plástico Duro & 2.687 & 3.942 & 4.920 \\
\hline Plástico Colorido & 2.080 & 20.741 & 4.424 \\
\hline Copo plástico & 1.873 & 1.728 & 4.330 \\
\hline Tetra Pak (leite, suco) & 1.036 & 2.453 & 4.781 \\
\hline Garrafa Pet & 1.975 & 2.562 & 6.821 \\
\hline Misto (revistas, jornais, livros, apostilas) & 22.262 & 32.218 & 60.312 \\
\hline Plástico Branco & 3.577 & 3.006 & 5.589 \\
\hline Vidros & 0 & 220 & 0 \\
\hline Rejeitos (material não aproveitado para re- & 13.797 & 20.067 & 24.366 \\
\hline ciclagem) & 0 & 90 & 0 \\
\hline Garrafinhas de plástico & $\mathbf{1 3 2 . 6 9 6}$ & $\mathbf{1 9 1 . 5 3 3}$ & $\mathbf{2 6 6 . 7 6 2}$ \\
\hline Total & & & \\
\hline Fonte: os propros autores. & & & \\
\hline
\end{tabular}

Fonte: os próprios autores.

Semelhante ao observado na UFU, a maior quantidade de resíduo gerado pela Universidade Federal de Brasília se refere ao papel branco e ao papelão. Conforme dados da Prefeitura Universitária da UNB, em 2015, foram descartados, mensalmente, em torno de $4.000 \mathrm{~kg}$ de papel branco, enquanto, na UFU, o descarte desse material foi, em média, $4.800 \mathrm{~kg}$ por mês (UNB, 2016).

Outro dado importante cedido pelas cooperativas de catadores com contrato firmado com a UFU foi o valor médio pago pelos materiais reciclados no ano de 2016. Os valores de venda dos anos anteriores não foram disponibilizados, pois as associações não detinham essa informação. Os valores estão descritos na Tabela 3. 
Tabela 3 - Valor de venda de materiais reciclados no ano de 2016 pelas cooperativas de catadores credenciadas pela UFU

\begin{tabular}{c|c}
\hline TIPO DE RESíDUOS & VALOR (R\$)/ $\mathbf{k g}$ \\
\hline Papelão & 0,55 \\
\hline Sucata (peças metálicas) & 0,07 \\
\hline Papel Branco & 0,45 \\
\hline Plástico Duro & 0,40 \\
\hline Plástico Colorido & 0,80 \\
\hline Copo plástico & 0,20 \\
\hline Tetra Pak (leite, suco) & 0,20 \\
\hline Garrafa Pet & 1,75 \\
\hline Plástico Branco & 1,35 \\
\hline
\end{tabular}

Fonte: os próprios autores.

Os catadores de materiais recicláveis podem ser considerados os grandes protagonistas da indústria de reciclagem no país, haja vista que eles detêm posição fundamental na gestão de RS no Brasil (GOUVEIA, 2012). Com a separação dos materiais recicláveis na UFU, o trabalho dos catadores foi consideravelmente facilitado, pois atualmente eles recebem os resíduos previamente selecionados. Além disso, a seleção na fonte geradora reduz o contato dos catadores de materiais recicláveis com material sujo e não higienizado, os quais podem causar contaminação e afetar a saúde humana. O fenômeno da reciclagem proporcionou um aumento do contingente populacional cuja renda principal advém da coleta dos resíduos. Em 2001, estimava-se que 500 mil pessoas coletavam resíduos no Brasil, e hoje acredita-se que um, a cada 1000 brasileiros, seja um catador (MELO; SOUTO, 2011).

\subsection{Avaliação dos impactos sociais, ambientais e econômicos}

A comprovação da viabilidade econômica de programas de coleta seletiva tem sido um grande desafio para gestores da área. Para analisar as vantagens econômicas e financeiras desses programas, devem-se considerar os custos e os benefícios resultantes do processo de coleta (AGUIAR; PHILIPPI JUNIOR, 2000; DEBORTOLI, 2007). 
O valor arrecadado e atualizado com a venda dos materiais coletados nos três campi da UFU, no período de três anos, foi de R\$231.252, 53. Além desse valor de venda, as associações receberam $\mathrm{R} \$ 183.206,00$ relacionados aos trabalhos de coleta e remoção desse material dos campi, totalizando $\mathrm{R} \$ 414.458,53$. Se não houvesse o sistema de coleta seletiva, esse material seria destinado ao lixo comum, deixando esse valor de ser arrecadado. Nesse sentido, a criação dessas cooperativas auxiliou na melhoria da qualidade de vida de diversas famílias que foram beneficiadas, bem como em virtude da contratação dessas cooperativas pela Universidade. Além disso, estas, com a venda desse material, conseguiram mais recursos para investir na aquisição de novos equipamentos para a triagem e melhoria de condições sanitárias e de trabalho dos catadores cooperados.

No ano de 2015, as associações de catadores obtiveram o valor atualizado de $\mathrm{R} \$ 90.849,29$ relacionado à venda de materiais, enquanto o valor

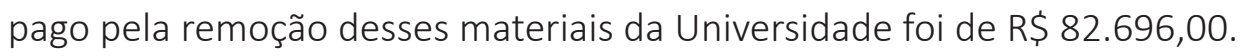
Esse dado começa a apontar para a viabilidade econômica dos programas de coleta seletiva, pois a renda obtida com a venda foi maior que o valor pago para a retirada do material. Além disso, estudos demonstraram que a reciclagem apresenta alta viabilidade sob o ponto de vista econômico, pois o setor movimenta cerca de R\$12 bilhões por ano, e acredita-se que, no Brasil, ainda se perdem mais de $\mathrm{R} \$ \mathbf{8}$ bilhões por ano devido ao não reaproveitamento de materiais, o que se deve à falta de consciência do cidadão comum sobre a reciclagem (INEAM, s.d.).

Outro fator importante a salientar é o tempo aproximado que os materiais levam para se decompor no meio ambiente, podendo ser citado o papelão, que demora cerca de 6 meses, as embalagens PET, cerca de 100 anos, e o plástico mais resistente, cerca de 450 anos (MAGALHÃES, 2001).

Pela realização da coleta seletiva da UFU, por exemplo, cerca de 11 toneladas de plástico mais resistente, que demorariam cerca de 450 anos para se decompor, deixaram de ser depositadas diretamente na natureza, reduzindo assim o impacto ambiental. Além disso, como receberam destinação adequada, os resíduos coletados não se transformaram em agentes poluentes diretos, minimizando, dessa forma, os danos ao meio ambiente e a consequente degradação dos recursos naturais. 
Embora não seja parte do escopo inicial da proposta, também foi observada a melhoria na qualidade de vida da comunidade acadêmica, dos trabalhadores das associações e da população local, em virtude dos benefícios à saúde humana, uma vez que o destino adequado dos resíduos é capaz de reduzir o surgimento de doenças relacionadas à sua inadequada disposição e seu manejo (INEAM, s.d.).

Os catadores também têm papel fundamental na preservação, pois esse grupo de trabalhadores vem atuando de maneira informal ou organizada em cooperativas e, mesmo antes da definição de políticas públicas claras para a gestão de resíduos no país, esses grupos vêm realizando um trabalho de grande importância ambiental, contribuindo significativamente para o retorno de diferentes materiais para o ciclo produtivo, gerando economia de energia e de matéria-prima e evitando que diversos materiais sejam destinados a aterros comuns (GOUVEIA, 2012).

Pode-se dizer que a reciclagem é uma forma relativamente simples de reduzir a necessidade de produção de novos materiais e, consequentemente, de diminuir o impacto ambiental. Para ilustrar essa afirmação, temos que, quando se reciclam $50 \mathrm{~kg}$ de papel, o corte de uma árvore é poupado (BRASIL, 2008). Em uma comparação genérica, no caso da UFU, foram coletadas 321 toneladas de papel/papelão, e assim poderiam ser poupadas 6.420 árvores.

A utilização de material reciclado também representa significativo benefício econômico para os custos dos insumos. A produção de uma tonelada de plástico gera um custo de $\mathrm{R} \$ 1.790,00$, e uma tonelada de plástico reciclado gera um custo de $\mathrm{R} \$ 626,00$. Já para produzir uma tonelada de celulose, o custo é de $\mathrm{R} \$ 687,00$, enquanto uma tonelada de papel reciclado custa $\mathrm{R} \$ 357,00$ para ser produzida. A análise desses dados revela o quanto a proporção do ganho é elevada quando se pratica a reciclagem (IPEA, 2013). Além disso, para fabricar uma tonelada de papel, além das árvores, ainda são utilizados 10 mil litros de água e energia, enquanto que, para ser produzida uma tonelada de papel reciclado, é necessária apenas uma tonelada e meia de papel velho, dois mil litros de água e metade da energia utilizada para fabricação do papel novo (CAPITAL RECICLÁVEIS, 2016). 
As ações voltadas para a gestão integrada de RS contribuíram para a geração de empregos e o aumento da renda dos catadores de materiais recicláveis associados, para o fortalecimento e a organização do grupo, bem como para o reconhecimento desses profissionais pela comunidade acadêmica como verdadeiros agentes da gestão ambiental. Tal fato é contrário ao que ocorre com a maioria dos catadores de materiais recicláveis que, apesar de terem sua profissão reconhecida pelo Ministério do Trabalho e Emprego, são alvo de grande preconceito social.

Para Gómez, Aguado e Pérez (2011), devido aos problemas ambientais existentes, é extremamente necessária a capacitação de profissionais para atuar nessa divisão social, com o objetivo de incluí-los no mercado de trabalho, proporcionando o resgate de sua integridade e dignidade, bem como garantir seus direitos como trabalhadores remunerados.

\subsection{Desenvolvimento do Guia de Coleta Seletiva de Resíduos Sólidos para Universidades Brasileiras}

Após serem avaliados os custos e os impactos da implantação do sistema de coleta seletiva da UFU, o qual se utilizou como modelo, foi desenvolvido o Guia de Coleta Seletiva de Resíduos, denominado "UNIVERSIDADE SUSTENTÁVEL". A partir da apresentação da Política Nacional de Resíduos Sólidos e legislação correlata, o Guia oferece uma breve conceituação sobre o que é Coleta Seletiva e suas vantagens, exemplificando o tempo de degradação de alguns resíduos sólidos mais comuns.

Na sequência, estão abordadas as etapas a serem percorridas para a implantação de um projeto de coleta seletiva, as quais envolvem o planejamento, a implantação propriamente dita e a manutenção do sistema, com a disponibilização de um passo-a-passo que permite a visualização rápida e didática do processo. Após recomendações gerais, o Guia traz Referências Bibliográficas para que o interessado possa buscar mais informações sobre o tema ${ }^{1}$.

\footnotetext{
${ }^{1}$ Para acessar o Guia basta acessar o link: https://universidadebrasil.edu.br/portal/_biblioteca/uploads/20190201181047.pdf
} 


\section{CONCLUSÕES}

Com a realização deste trabalho, demonstrou-se a importância e as vantagens da implantação de um sistema de coleta seletiva em universidades. Além da contribuição para redução dos impactos ambientais negativos, acredita-se que um dos principais benefícios observados a partir da execução dessas ações seja o incremento social associado à comercialização do material coletado pelas várias famílias envolvidas no processo. Além disso, como consequência, as cooperativas aumentaram os recursos para investir na aquisição de novos equipamentos e assim melhorar as condições sanitárias e de trabalho dos catadores cooperados, demonstrando, junto com os índices positivos alcançados, a viabilidade econômica destes programas.

Entretanto devemos destacar que a efetividade de um sistema de coleta seletiva em universidades só será possível com a mudança de percepção dos envolvidos, o que pode ser alcançado por meio da implantação de projetos de educação ambiental, de modo que esses indivíduos passem a vislumbrar o meio ambiente de outra forma, quebrando preconceitos e se tornando partícipes mais conscientes do seu papel na sociedade.

\section{REFERÊNCIAS}

AGUIAR, A.; PHILLIPPI, J. A. Custos de coleta seletiva: critérios de apuração e viabilidade dos programas. In: CONGRESSO INTERAMERICANO DE ENGENHARIA SANITÁRIA E AMBIENTAL, 27., Porto Alegre, RS. Anais [...]. Rio de Janeiro: ABES, 2000.

BITTENCOURT, P. T. Metodologia de elaboração do Plano de Gerenciamento de Resíduos Sólidos da UFSC Campus Florianópolis. 2014. 116f. Orientadora: Sara Meireles. Trabalho de Conclusão de Curso (Graduação em Engenharia Sanitária e Ambiental) - Centro Tecnológico, Universidade Federal de Sana Catarina, Florianópolis, SC, 2014.

BRASIL. Ministério do Meio Ambiente. Coleta seletiva solidária- cidadania, oportunidade de renda e inclusão social, 2008. Disponível em: http://a3p.ana. gov.br/Documents/docs/outros/cartilha_coleta\%20nov-2008.pdf. Acesso em: 26 set. 2016. 
CAPITAL RECICLÁVEIS. Curiosidades. [s.d.]. Disponível em: http://www. capitalreciclaveis.com.br/navegacao. asp?id=18\&pagina=Curiosidades. Acesso em: 26 out. 2016.

CARETO, H.; VENDEIRINHO, R. Sistemas de gestão ambiental em universidades: caso do Instituto Superior Técnico de Portugal. Relatório final de curso, p. 20022003, 2003. Disponível em: http://meteo.ist.utl.pt/ jjdd/LEAMB/LEAmb\%20 TFC\%20site\%20v1/2002-003/HCareto_RVendeirinho\%20artigo.pdf. Acesso em: 8 dez. 2016.

COMISSÃO EUROPÉIA. A EU e a gestão de resíduos. Luxemburgo: Serviço das Publicações Oficiais das Comunidades Europeias, 2000. 18 p.

DEBORTOLI, R. Benefícios econômicos e ambientais da coleta seletiva de Biguaçu. Orientador: José Alonso Borba. 2007. 56f. Monografia (Bacharelado em Ciências Contábeis ) - Universidade Federal de Santa Catarina (UFSC), Florianópolis, SC, 2007.

FURIAM, S. M.; GÜNTHER, W. R. Avaliação da educação ambiental no gerenciamento dos resíduos sólidos no campus da Universidade Estadual de Feira de Santana. Revista Sitientibus, Feira de Santana, BA, v. 35, p. 7-27, jul./dez. 2006.

GÓMEZ, J. A. D.; AGUADO, O. V.; PÉREZ, A. G. (Org.). Serviço social e meio ambiente. 4. ed. São Paulo: Cortez. 2011. 135p.

GOUVEIA, N. Resíduos sólidos urbanos: impactos socioambientais e perspectiva de manejo sustentável com inclusão social. Ciência \& Saúde Coletiva, Rio de Janeiro, v. 17, n. 6, p. 1503-10, 2012.

GRIPPI, S. Lixo, reciclagem e sua história-guia para as prefeituras brasileiras. Rio de Janeiro: Interciência, 2001. Disponível em: http://bases.bireme.br/cgi-bin/ wxislind.exe/iah/online/?IsisScript=iah/iah. $x i s \& s r c=g o o g l e \& b a s e=L I L A C S \& l a n g=p$ \&nextAction=Ink\&exprSearch=415591\&indexSearch=ID. Acesso em: 19 out. 2016.

INSTITUTO NACIONAL DE EDUCAÇÃO AMBIENTAL. Reciclagem movimenta 12 bilhoes por ano. [s.d.]. Disponível em: http://ineam.com.br/reciclagem-movimentar-12-bilhoes-por-ano-no-brasil/. Acesso em: 13 dez. 2016.

INSTITUTO DE PESQUISA ECONÔMICA E APLICADA. Diagnóstico dos resíduos sólidos industriais. Brasília: IPEA, 2012. 
INSTITUTO DE PESQUISA ECONÔMICA E APLICADA. Relatório da situação social das catadoras e dos catadores de material reciclável e reutilizável. Brasília: IPEA, 2013.

MAGALHAES, M. A. Tempo de degradação de materiais descartados no meio ambiente. Jornal do Centro Mineiro para Conservação da Natureza (CMCN), Viçosa, MG, ano 08, n. 37, jan./fev./mar. 2001.

MELO, J. A.; SOUTO, J. V. Interfaces no trabalho dos catadores de materiais recicláveis: relações complexas com o Estado e o capital. Temporalis, Brasília, v. 1, n. 21, p. 49-70, 2011.

RODRIGUES, E. T.; LEITE, J. F. Proposta de implementação da coleta seletiva de resíduos [com o aproveitamento de garrafas pets e latas de alumínio]: no condomínio residencial Prive das Laranjeiras, Goiânia, GO. 2008. Disponível em: www.agu.gov.br/page/download/index/id/19461321. Acesso em: 13 dez. 2016.

TAUCHEN, J.; BRANDLI, L. A gestão ambiental em instituições de ensino superior: modelo para implantação em campus universitário. Gestão \& Produção, São Carlos, SP, v. 13, n. 3, p. 503-515, 2006.

UNIVERSIDADE FEDERAL DE BRASÍLIA. Guia da coleta seletiva solidária na UNB. Brasília: UNB, 2016. Disponível em: http://fup.unb.br/wp-content/ uploads/2016/08/cartilha_coleta_seletiva_virginia.pdf. Acesso em: 11 nov. 2016. 